\title{
Sustainable Economic Growth and Exhaustible Resources: A Model and Estimation for the US
}

\author{
ALMUTH SCHOLL ${ }^{\mathrm{a}, *}$ and WILLI SEMMLER ${ }^{\mathrm{b}, \mathrm{c}}$ \\ ${ }^{\mathrm{a}}$ Department of Economics, Humboldt University, Berlin, Germany; ${ }^{\mathrm{b}}$ Center of Empirical Macroeconomics, Bielefeld, Germany \\ ${ }^{\mathrm{c}}$ New School University, NY, USA \\ (Revised 14 April 2001)
}

\begin{abstract}
This paper studies current models on sustainable economic growth with resource constraints and explores to what extent resource constraints can be overcome by substitution and technological change. We also study the problem of intergenerational equity and the different criteria that have been suggested in the literature. The central part of this paper is the presentation of stylized facts on exhaustible resources and an estimation of a basic model with resource constraints for US time series data. The estimated years left until depletion and the empirical trends of the ratios of capital stock and consumption to resources seem to indicate that there might be a threat to sustainable growth in the future. In our estimation, we obtain parameter values, which help to interpret the extent to which growth with exhaustible resources is sustainable.
\end{abstract}

Keywords: Resource; Consumption; Intergenerational; Economic growth

\section{INTRODUCTION}

Since the early 1970 s, there is a growing concern that human activity depletes resources and pollutes the environment. As economic decisions are restricted by the finiteness of natural resources, and by the limited capacity of the nature to absorb pollution, attention is devoted to the question whether it is possible and desirable to continue present patterns of economic growth.

In 1972, economists like Meadows et al. (1972) or Daly $(1987,1989)$ formulated pessimistic predictions about a "sudden and uncontrollable decline in both population and industrial capacity" if no "conditions for ecological and economic stability that is sustainable far into the future" are established. $\dagger$ Other economists like Beckerman (1974) have the optimistic view that technological progress and the discovery of new substitutes make continued economic growth possible. A general consensus of the economic growth debate is that there are trade-offs among environmental and economic goals. The agreement is that economic activity, which ignores the biological or social system, is not sustainable. There exist many different definitions of sustainability, but all of them have two points in common. First, they recognize that resource and environmental constraints affect the patterns of development and consumption in the long-run. Second, they are concerned about equity between generations (intergenerational equity). One of the most famous definitions is stated by the Brundtland Commission in 1987: "sustainable development is development that meets the needs of the present without compromising the ability of future generations to meet their own needs." Similarly Solow $(1974)^{*}$ defines sustainablity as "an obligation to conduct ourselves so that we leave to future the option or the capacity to be as well off as we are." Pearce et al. (1990) point out that "natural capital stock should not decrease over time" whereas Pezzey (1989) defines sustainable economic growth as "non-declining output or consumption over time" and sustainable economic development as "non-declining utility over time."*

As to the sustainability of natural resources, one can distinguish between renewable and non-renewable resources. Dynamic models on renewable resources can be found in Clark (1990), Semmler and Sieveking (1994) and Sieveking and Semmler (1997). In those papers, theorems on the sustainability of resource economics, which have been developed by studying one resource, only are evaluated for the case when resources interact as an

\footnotetext{
*Corresponding author.

${ }^{\dagger}$ Meadows et al., 1972, p. 23.

*see also Nordhaus 1992.

*see also Solow $(1991,1992)$.
} 
ecological system. For the latter case, resource management problems and policies aiming at conserving resources are studied. Furthermore, in Semmler and Sieveking (1994), credit financed extractions of resources are considered and the fate of resources explored.

The current paper deals with dynamic models with exhaustible resources. We discuss prototype growth models that incorporate and study the consequences of finitely available exhaustible resources. Some of the problems studied here will also arise in the case of renewable resources, so for example, the problem of intergenerational justice. The remainder of the paper is organized as follows. In the second section, we survey growth models with natural resource constraints. The third section discusses the problem of intergenerational justice. The fourth section presents stylized facts on exhaustible resources pertaining to the US. The fifth section presents the estimation of our growth model and the sixth section concludes the paper.

\section{MODERN GROWTH MODELS AND RESOURCE CONSTRAINTS}

We here review growth models, which take into account the presence of exhaustible natural resources. The main interest of the analysis is the question to what extent the process of economic growth is restricted by the finiteness of resource stocks and whether sustained consumption and utility levels are feasible.

We first consider a basic model where the exhaustible natural resource is used as an input for the production of a good, which is then either consumed or added to the capital stock to enhance future production. Then, the consequences of different extensions concerning technological progress are analyzed, and, finally, it is assumed that natural resources may provide services in preserved states.

Before turning to the description of the models, it is important to have a clear distinction between renewable and exhaustible resources. The main feature of an exhaustible resource is that its growth rate is nil, and that it is not recyclable. Furthermore, it is used up when used as an input in production. To study a meaningful economic problem, the natural resource must be essential, i.e. production is impossible without it.

\section{The Basic Model}

Dasgupta and Heal (1974), Heal (1985), Stiglitz (1974; 1993) and Solow (1973) analyze the optimal depletion of exhaustible natural resources in the context of a growth model where the resource is used as an input for the production of a composite commodity.* The production function $F$ depends on the flow of the exhaustible resource at date $t$ and on the stock of a reproducible good at date $t$. In order to obtain greatest possible social welfare, the present value of utility $U$ derived from consumption $C_{t}$ of the produced good is maximized subject to the evolution of the reproducible capital stock $K_{t}$ and the constraints imposed by the finiteness of the resource stock $S_{t}$ :

$$
\operatorname{Max} \int_{0}^{\infty} U\left(C_{t}\right) \mathrm{e}^{-\delta t} \mathrm{~d} t
$$

Subject to

$$
\begin{gathered}
\dot{K}_{t}=F\left(K_{t}, R_{t}\right)-C_{t} \\
S_{t}=S_{0}-\int_{0}^{\infty} R_{t} \mathrm{~d} t \quad \dot{S}_{t}=-R_{t}
\end{gathered}
$$

$\delta$ denotes the discount rate, and $R_{t}$ is the flow of the exhaustible resource. The initial capital stocks $K_{0}$ and $S_{0}$ are strictly positive and given. The production function $F\left(K_{t}, R_{t}\right)$ is assumed to be increasing, strictly concave, twice continuously differentiable and homogenous of degree unity. The utility function $U\left(C_{t}\right)$ is supposed to be strictly concave, and for $C_{t} \rightarrow 0$, its first derivative is infinity. Here, the extraction of the resource is assumed to be costless.

Solving the maximization problem and combining the optimality conditions yields the following results (for details see "The Basic Model" section in the Appendix A): first, along an optimal path, the rate of consumption depends on the discount rate $\delta$, on the elasticity of marginal utility of consumption $\eta$ and on the marginal productivity of reproducible capital $F_{K}$ :

$$
\frac{\dot{C}_{t}}{C_{t}}=\frac{F_{K}-\delta}{\eta}
$$

with $\eta\left(C_{t}\right)=-C_{t} U^{\prime \prime}\left(C_{t}\right) / U^{\prime}\left(C_{t}\right) \quad$ and $\quad F_{K}=$ $\partial F\left(K_{t}, R_{t}\right) / \partial K_{t}$. Equation (2) states that the higher the discount rate, the more the rate of consumption falls over time along an optimal path. Second, along an optimal path, the rates of return of exhaustible and reproducible capital are equal:

$$
F_{K}=\frac{\partial F_{R}}{\partial t} \frac{1}{F_{R}}
$$

with $F_{R}=\partial F\left(K_{t}, R_{t}\right) / \partial R_{t}$. If the production function is homogenous of degree one, it is possible to set $x_{t}=K_{t} / R_{t}$ with $f\left(x_{t}\right)=F\left(K_{t} / R_{t}, 1\right)$. Substituting $\quad F_{R}=f\left(x_{t}\right)-$ $x_{t} f^{\prime}\left(x_{t}\right)$ and $F_{K}=f^{\prime}\left(x_{t}\right)$ in Eq. (3) yields the following capital-resource ratio along an optimal path:

$$
\frac{\dot{x}_{t}}{x_{t}}=\sigma \frac{f\left(x_{t}\right)}{x_{t}}
$$

with

$$
\sigma=\frac{-f^{\prime}\left(x_{t}\right)\left(f\left(x_{t}\right)-x_{t} f^{\prime}\left(x_{t}\right)\right)}{x_{t} f\left(x_{t}\right) f^{\prime \prime}\left(x_{t}\right)}
$$


as the elasticity of substitution between reproducible capital and the exhaustible resource. Equation (4) represents the rate at which reproducible capital is substituted for the exhaustible resource. It depends on the elasticity of substitution and on the average product per unit of fixed capital.

In order to conclude whether a positive level of consumption is sustainable over time, Dasgupta and Heal (1974) analyze an economy where output is produced by a CES-production function, i.e. the case of a constant elasticity of substitution. There are three cases to mention:

1. $\sigma=1$ (i.e. the Cobb-Douglas-production function). The exhaustible resource is essential and infinitely valuable at the margin, whereas the asymptotic value of marginal productivity of capital is zero. Solow (1973) concludes that sustained per capita consumption is feasible if the share of capital exceeds that of natural resources.

2. $0 \leq \sigma<1$. The exhaustible resource is essential, but finitely valuable at the margin. Thus, a positive and non-decreasing level of consumption over an infinite time horizon is not sustainable.

3. $\infty>\sigma>1$. Sustained consumption is feasible because in this case, the exhaustible resource is inessential.

\section{Technology}

The basic model can be augmented by introducing technical change, which makes it easier to find new substitutes in order to render an essential natural resource inessential. Dasgupta and Heal (1974) assume that technical progress is uncertain: the exact date of discovering a substitute and its detailed characteristics and usefulness are unknown. The new technique is supposed to occur at an unknown date $T$ which is a random number with an exogenously given probability density function $\omega_{t}$ :

$$
\text { Probability }(T=t)=\omega_{t}, \quad \int_{0}^{\infty} \omega_{t} \mathrm{~d} t=1, \quad \omega_{t}>0
$$

In order to express the situation of uncertainty, the objective is to maximize the expected present value of utility. After some manipulation, one obtains the following maximization problem ๆ:

$$
\operatorname{Max} \int_{0}^{\infty}\left[U\left(C_{t}\right) \Omega_{t}+\omega_{t} W\left(K_{t}, S_{t}\right)\right] e^{-\delta t} \mathrm{~d} t
$$

subject to

$$
\dot{K}_{t}=F\left(K_{t}, R_{t}\right)-C_{t}, \quad S_{t}=S_{0}-\int_{0}^{\infty} R_{t} \mathrm{~d} t \quad \dot{S}_{t}=-R_{t}
$$

"Dasgupta, 1994 pp. 20.

${ }^{\S}$ See also Sieveking and Semmler, 1997. with $\Omega_{t}=\int_{t}^{\infty} \omega_{t} \mathrm{~d} t$ and

$$
W\left(K_{t}, S_{t}\right)=\operatorname{Max} \int_{T}^{\infty} U\left(C_{t}\right) e^{-\delta[t-T]} \mathrm{d} t .
$$

$K_{t}, C_{t}, R_{t}$ and $S_{t}$ are all non-negative and the initial values $K_{0}$ and $S_{0}$ are given.

Solving the maximization problem, combining the first order conditions, and arguing that at the discovery date of the substitute, the then existing stocks of reproducible and natural capital have no economic value anymore because the new technology is more efficient (i.e. $W_{K}=W_{S}=0$ ), allows for the following conclusions (for details, see "Technology" section in Appendix A): first, along an optimal path, the rate of consumption depends on a modified discount rate:

$$
\frac{\dot{C}_{t}}{C_{t}}=\frac{F_{K}-\left(\delta+\psi_{t}\right)}{\eta}
$$

with $\psi_{t}=\omega_{t} / \Omega_{t}$ as the conditional probability of the technological breakthrough at date $t$, given the substitute has not been discovered earlier. The discount rate is modified by the addition of the factor $\psi_{t}$ showing the probability of the essential resource becoming inessential as a result of technical progress. Thus, in a situation of uncertainty, the discount rate is higher than in a situation of certainty. ${ }^{\S}$ Obviously, the equation describing the ratio of capital-resource input is the same as before:

$$
\frac{\dot{x}_{t}}{x_{t}}=\sigma \frac{f\left(x_{t}\right)}{x_{t}}
$$

Stiglitz (1974, 1993) examines an economy where output is produced by a Cobb-Douglas-production function. He concludes that sustained per capita consumption is feasible, if there is a resource augmenting technical change at any positive rate (for $\sigma \geq 1$ ). Toman et al. (1993) point out that for the case $\sigma<1$, sustained per capita consumption is possible if technological progress is high enough.

\section{Backstop Technology}

So far, it is assumed that the natural resource is exhaustible, i.e. once it is used up, it is impossible to find more, and that the extraction is costless. As an extension, it is now supposed that the resource is available in unlimited quantities, but at various grades and various costs. For example, the ores of a number of metals can be extracted from the deposits currently used, which are exhaustible. If they are used up, the metals themselves can be extracted from the sea or from rock formations, which is much more expensive. Thus, at higher prices, the natural resource may be of unlimited availability. Heal (1993) 
calls this a backstop technology.* We can incorporate it into the basic model described in "The Basic Model." The total amount of the resource used at date $t$ is denoted as follows:

$$
z(t)=\int_{0}^{\infty} R_{t} \mathrm{~d} t
$$

It is assumed that at date $T$, the conventional deposits are exhausted and a backstop technology takes over. Up to the level $z_{T}$, the extraction costs rise with cumulative extraction, then the backstop technology is available at a constant cost per unit $b . g\left(z_{t}\right)$ denotes the extraction costs per unit at date $t$ with $\partial g / \partial z_{t}=g^{\prime}\left(z_{t}\right)>0$ for $0 \leq z_{t} \leq z_{T}$ and $g\left(z_{T}\right)=b>0$ for $z_{t} \geq z_{T}$.

The maximization problem is solved in two steps (see "Backstop Technology" section in Appendix A): first, the situation is examined before current deposits are exhausted (maximization problem (8)), second, the situation is examined after the backstop technology has taken over (maximization problem (9)):

$$
\operatorname{Max} \int_{0}^{\infty} U\left(C_{t}\right) e^{-\delta t} \mathrm{~d} t
$$

subject to

$$
\begin{gathered}
\dot{K}_{t}=F\left(K_{t}, R_{t}\right)-C_{t}-g\left(z_{t}\right) R_{t} \\
S_{t}=S_{0}-\int_{0}^{\infty} R_{t} \mathrm{~d} t, \quad \dot{S}_{t}=-R_{t}
\end{gathered}
$$

where $g\left(z_{t}\right) R_{t}$ represents the total extraction costs.

$$
\operatorname{Max} \int_{0}^{\infty} U\left(C_{t}\right) e^{-\delta t} \mathrm{~d} t
$$

subject to

$$
\dot{K}_{t}=F\left(K_{t}, R_{t}\right)-C_{t}-b R_{t}
$$

The initial capital stocks $K_{0}$ and $S_{0}$ are strictly positive and given. Computing the conditions along an optimal path of problem (8) yields:

$$
\frac{\dot{C}_{t}}{C_{t}}=\frac{F_{K}-\delta}{\eta}
$$

and

$$
F_{K}=\frac{\partial F_{R}}{\partial t} \frac{1}{F_{R}}+\frac{F_{K} g\left(z_{t}\right)}{F_{R}}
$$

Substituting $F_{K}=f^{\prime}\left(x_{t}\right)$ and $F_{R}=f\left(x_{t}\right)-x_{t} f^{\prime}\left(x_{t}\right)$ with $f\left(x_{t}\right)=F\left(K_{t} / R_{t}, 1\right)$ results in the following capital-resource ratio along an optimal path:

$$
\frac{\dot{x}_{t}}{x_{t}}=\frac{\sigma f\left(x_{t}\right)}{x_{t}}+\frac{f^{\prime}\left(x_{t}\right)}{x_{t} f^{\prime \prime}\left(x_{t}\right)} \frac{g\left(z_{t}\right)}{x_{t}}
$$

Condition (12) is a generalization of condition (4). Here, the equation is augmented by the term $\left(f^{\prime}\left(x_{t}\right) / x_{t} f^{\prime \prime}\left(x_{t}\right)\right)\left(g\left(z_{t}\right) / x_{t}\right)$ which reflects the cumulative costs of extraction.

Following Heal (1993), we can draw the following conclusions. During the initial period, the lower-cost stocks of the natural resource are exhausted, and the path of the economy is described by problem (8) and conditions (10) and (11). The difference between prices and extraction costs, i.e. the user costs, decline until they reach zero at date $T$, when the backstop technology takes over because the lower-cost stocks are totally used up. From then on, the economy behaves according to problem (9) thus, the extraction costs of the natural resource always equal its price.

\section{INTERGENERATIONAL EQUITY}

As apparent from the above models, the depletion of resources generates externalities for future generations. Therefore, the problem of intergenerational equity arises. In order to study this problem, we will first show how natural resources may affect the welfare of the society.

\section{The Amenity Value of a natural Resource}

There are two ways of how a natural resource contributes to society's welfare. The models described so far refer to the first way: the resource is utilized as an input factor for the production of a composite commodity. The second way of a natural resource serving for the well-being of the society is that it may provide valuable services in preserved states, that is scientific, recreational, and aesthetic values. To take into account these so-called amenity values of natural resources, the resource stock $S_{t}$ is included in the utility function (Krautkraemer, 1985). The objective is to maximize present value of utility (see "The Amenity Value of a Natural Resource" section in Appendix A):

$$
\operatorname{Max} \int_{0}^{\infty} U\left(C_{t}, S_{t}\right) e^{-\delta t} \mathrm{~d} t
$$

subject to

$$
\dot{K}_{t}=F\left(K_{t}, R_{t}\right)-C_{t} \quad S_{t}=S_{0}-\int_{0}^{\infty} R_{t} \mathrm{~d} t \quad \dot{S}_{t}=-R_{t}
$$

where $C_{t}, K_{t}, R_{t}, S_{t}$ are all non-negative. $U\left(C_{t}, S_{t}\right)$ is assumed to be twice continuously differentiable with $U_{C}=\partial U\left(C_{t}, S_{t}\right) / \partial C_{t}>0$ and $\left.U_{S}=\partial U\left(C_{t}, S_{t}\right) / \partial S_{t}\right)>$ $0, U_{\mathrm{CC}}=\left(\partial^{2} U\left(C_{t}, S_{t}\right) / \partial C_{t}^{2}\right)<0$ and $U_{\mathrm{SS}}=\left(\partial^{2} U\left(C_{t}, S_{t}\right) /\right.$ 
$\left.\partial S_{t}\right)<0$ and

$$
\lim _{C_{t} \rightarrow 0} U_{C}=\infty
$$

The production function $F\left(K_{t}, R_{t}\right)$ has the same properties as before. Solving the maximization problem and combining the first order conditions yield the following conditions for the rate of consumption and for the capital-resource ratio along an optimal path:

$$
\begin{gathered}
\frac{\dot{C}_{t}}{C_{t}}=\frac{F_{K}-\delta-\left(U_{C S} / U_{C}\right) R_{t}}{\eta} \\
\frac{\dot{x}_{t}}{x_{t}}=\sigma \frac{f\left(x_{t}\right)}{x_{t}}+\frac{U_{S} / U_{C}}{x_{t}^{2} f^{\prime \prime}\left(x_{t}\right)}
\end{gathered}
$$

The amenity services of a natural resource affect the extraction and the consumption mainly through their contribution to the rate of return to the resource stock. Resource amenities enhance the value of the resource stock. Therefore, the initial price of the resource must be higher than in the previous models. Furthermore, since $f^{\prime \prime}\left(x_{t}\right)<0$, the amenity services lower the rate of change in the capital-resource ratio by the term $\left(\left(U_{S} / U_{C}\right) / x_{t}^{2} f^{\prime \prime}\left(x_{t}\right)\right)$. The higher the marginal rate of substitution between amenities and consumption, the higher the reduction of the rate of change of the input ratio.

In this framework where natural environments are valued in their own rights, the so-called Green Golden Rule ${ }^{\|}$can be introduced which is motivated by the Golden Rule of Economic Growth." The Golden Rule of Economic Growth gives the growth path with the highest indefinitely maintainable level of consumption, whereas the Green Golden Rule focuses on the highest indefinitely maintainable level of instantaneous utility. Thus, the Green Golden Rule incorporates the aim of sustainability. Formally, the rule can be written as ${ }^{* *}$ :

$$
\max _{\text {feasible paths }} \lim _{t \rightarrow \infty} U\left(C_{t}, S_{t}\right)
$$

If the resource is used as an input factor for the production of a composite commodity, in the long-run, the only constant level of resource input is zero. Since the resource is essential, no output can be produced and consumption is zero. Hence, the highest indefinitely maintainable utility level is feasible, if the total initial stock is conserved.

\section{Intergenerational Equity}

Standard growth models, which incorporate the concept of sustainability, focus on the consequences of natural resource constraints on the long-run pattern of economic development and consumption. In order to determine inter-temporal welfare, recent growth theory has used the concept of discounted utilitarism that is the future is discounted in comparison with the present. Ramsey (1928) states that discounting is "ethically indefensible and arises merely from the weakness of the imagination" because a positive discount rate results in an asymmetric treatment of present and future generations. Thus, discounted future utility neglects intergenerational equity as the second important point of the concept of sustainability. In the following, we want to give a brief review of some alternative concepts, which try to meet the objective of a fair treatment of different generations.

A simple way to account for intergenerational equity is to assume the case of a zero utility discount rate, that is present and future generations are given the same weight. Another alternative is to apply the "overtaking criterion" as proposed by Weizäcker (1967), which states that one consumption path is better than another, if from some date on total utility of that path is greater. Formally, if

$$
\int_{0}^{T} U\left(C_{t}^{1}\right) \mathrm{d} t \geq \int_{0}^{T} U\left(C_{t}^{2}\right) \mathrm{d} t
$$

But applying these approaches gives rise to technical problems. For a zero discount rate, the set of attainable values of the integral may be open, and the way of ranking consumption paths according to the overtaking criterion is incomplete.

According to the Rawlsian Criterion ${ }^{\dagger \dagger}$ intergenerational equity means: maximize the welfare of the less advantaged generation. Formally,

$$
\max _{\text {feasible paths }} \min _{\text {generationst }}\left(\text { Welfare }{ }_{t}\right)
$$

The consequence of this decision rule is that the welfare level should be the same for all generations. If a later generation enjoys higher welfare, an earlier generation should increase its own welfare at the expense of the later generation and vice versa. Solow (1973) points out that in comparison with the discounted solution based on utilitarism, the Rawlsian Criterion will use up the natural resource stock faster. Since the utilitarian rule demands higher savings, earlier generations will have a lower standard of living than the constant max-min rule would generate. ${ }^{*}$ The Rawlsian Criterion has two main difficulties: first, a society needs an initial capital stock high enough to make a decent standard of living possible, but the explanation of its existence is missing. Second, the rule does not yield a reasonable result, if ongoing technical progress is assumed."

\footnotetext{
"Chichilnisky, 1996; Beltratti et al. 1994, 1993, 1995, 1996.

\#Phelps, 1961.

${ }^{* *}$ Heal, 1998, p. 43.

${ }^{\dagger}$ Rawls, 1972.

${ }^{*}$ See also Dixit et al. (1980), Hartwick (1977).

\#A more elaborate version of the Rawls criterion is proposed in Semmler and Sieveking, 2000.
} 
More recently, Chichilnisky (1996) defines two axioms for sustainability, which deal with the problem of intergenerational equity. The first axiom states that the present generation should not dictate the outcome in disregard for the future. The second axiom states that the long-run future should not dictate the present. Welfare criteria, which do satisfy the two axioms, are called sustainable preferences. In order to formulate a criterion, which does belong to the class of sustainable preferences, positive weight is placed on the present and on the very long-run properties of a growth path. Formally,

$$
\alpha \int_{0}^{\infty} U\left(C_{t}, S_{t}\right) \Delta(t) \mathrm{d} t+(1-\alpha) \lim _{t \rightarrow \infty} U\left(C_{t}, S_{t}\right)
$$

where $\alpha \in(0,1) . \Delta(t)$ is any measure with $\int_{0}^{\infty} \Delta(t) \mathrm{d} t=1$. If $\Delta(t)=\mathrm{e}^{-\delta t}$, the first term is just the discounted integrals of utilities. The second term reflects the limiting properties of the utility stream, and it has already been mentioned as the Green Golden Rule solution. The Chichilnisky Criterion places more weight on the future than the standard approach of discounting utility, but less than the Green Golden Rule. It is possible to apply the Chichilnisky Criterion to neoclassical growth models at the aforementioned type ${ }^{\text {ๆ }}$ but finding the solution is quite complicated. We therefore leave aside detailed discussions.

This very short review of different welfare criteria has shown that it is very difficult to find approaches, which do meet the objective of permitting intergenerational equity and which are technically operable at the same time. For that reason, discounted utility is still dominant, as it is the technically most convincing approach, though it favors the present over the future.

\section{STYLIZED FACTS}

Economic theory states that substitution possibilities, technological progress and the value of the resource in preserved states may prevent the total depletion of natural capital. In this section, the patterns of some selected nonrenewable resources of the US economy are analyzed from 1960 to 1995. This then serves as background for our estimations in the next section. Here, extraction rates, resource quantities available today and in the future are examined with respect to the question whether there are reasons to argue that the resources will be soon exhausted or that improved technology and the development of reproducible substitutes make a sustainable economic development possible.

Two different kinds of natural resources fulfill the main characteristics of depletion: fuel minerals such as energy resources, and non-fuel minerals such as metals and industrial minerals. When talking about the limited availability of natural resources, it is important to have

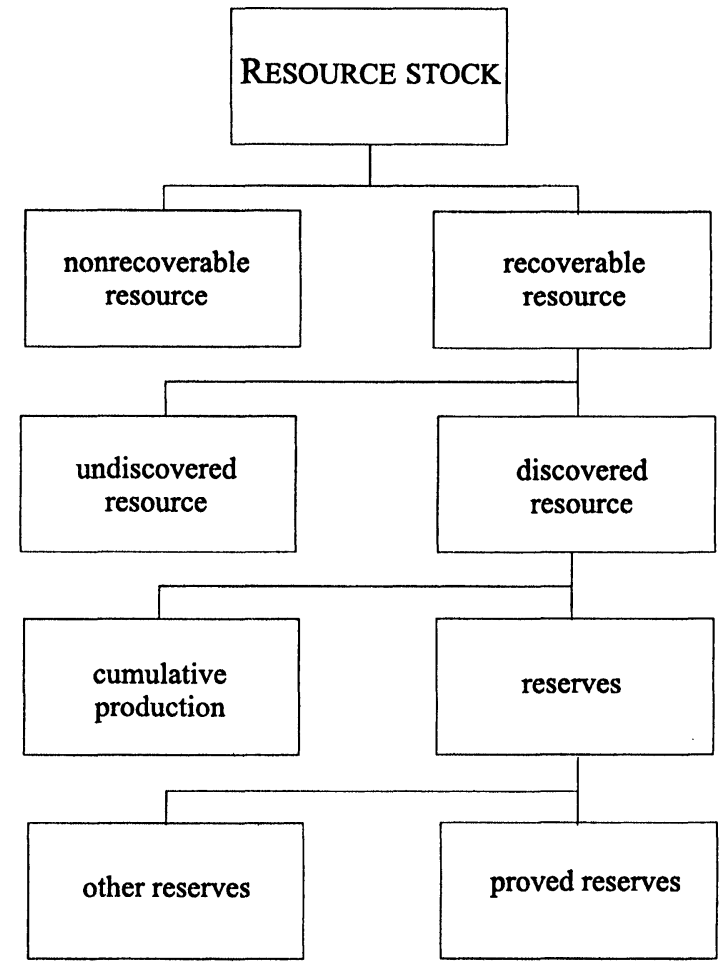

FIGURE 1 The components of resource stock.

clear definitions of the different components of which the total resource stock consists. Figure 1 explains the different components.

The reserves of the discovered resources consist of proved reserves and other reserves such as inferred reserves (field growth), measured reserves and indicated reserves. Proved reserves are those amounts of the resource that geological and engineering data demonstrate with reasonable certainty to be recoverable in the future from known reservoirs under existing economic and technological conditions. The other reserves consist on one hand of that part of the identified economically recoverable resource that will be added to proved reserves in the future through extensions, revisions and the discovery of new fields in already discovered regions, and on the other hand, on those quantities of the resource that may become economically recoverable in the future from existing production reservoirs through the application of currently available, but as-yet uninstalled recovery technology. ${ }^{\& 8}$ For details on the data sources for the subsequent summaries, see Appendix B.

As noted before, fuel minerals are energy sources such as crude petroleum, coal and natural gas. Since during the last 30 years, the US economy has experienced continued economic growth, that is a rising level of real GDP, total energy consumption has increased by roughly $35 \%$. To satisfy increasing energy demand, the production of

\footnotetext{
$"$ For a detailed analysis see Heal, 1995.

${ }^{\S \S}$ For definitions see Energy Information Administration, (1996; 1997).
} 


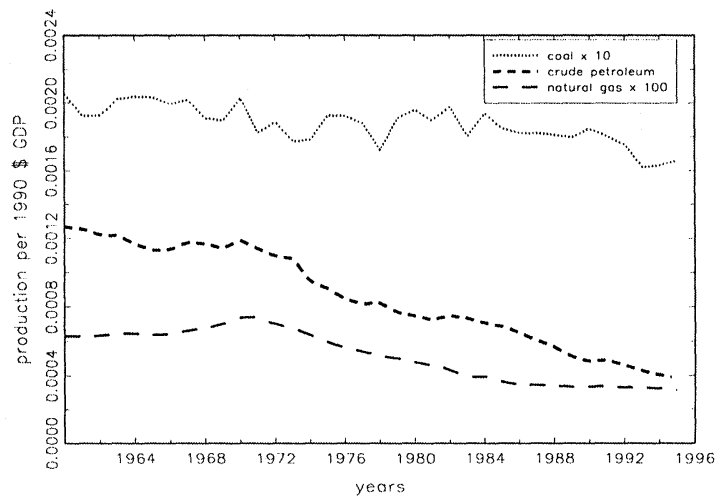

FIGURE 2 Fuel: mineral production per 1990 \$ GDP (coal production measured short tons, crude petroleum production measured in barrels, natural gas production measured in millions of cubic feet).

especially coal and natural gas have risen. In order to draw conclusions whether the resources are used more efficiently over time, it is interesting to analyze the patterns of production rates per dollar of real GDP, see Fig. 2. Table I summarizes the results.

For every energy resource, the production rates per GDP are falling, i.e. crude petroleum, coal and natural gas are used more efficiently today, which may be the result of improved technology. Non-fuel minerals are on one-hand metals and on the other hand, industrial minerals. Here, only some selected metals such as copper, iron ore, lead and zinc are analyzed. The production rates of copper, iron ore, lead and zinc behave quite irregularly from 1960 to 1995 and no trends can be determined.

Figure 3 and Table II show that the production rates per dollar real GDP are decreasing. Exhaustible energy resources can be substituted by renewable energy sources like for example, wind and sun power.

Figure 4 shows the shares of the different energy sources. Today, nuclear power and renewable energy together are just $20 \%$ of total energy production. But the trend is that the production of crude petroleum, coal and natural gas is decreasing, while nuclear and renewable energy production is increasing.

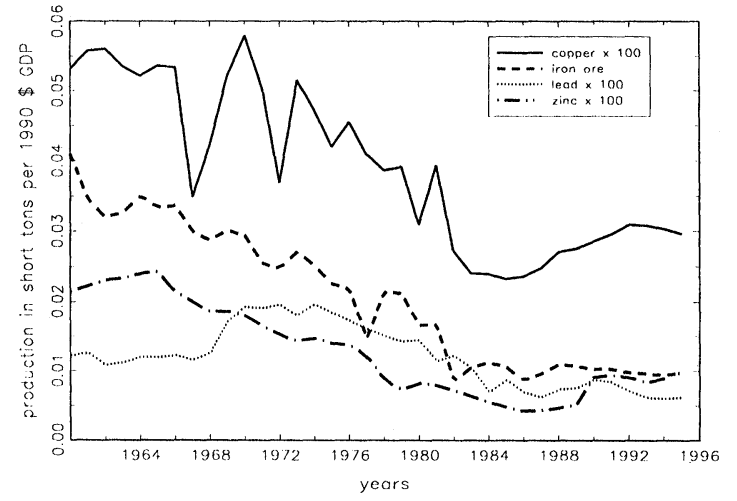

FIGURE 3 Metal: production per GDP (metal production in short tons).

Copper, lead and zinc are metals, which can be substituted by aluminum and plastic. For iron ore, there do not exist any substitutes, but as it will be shown later, the reserves of iron ore are very high and will last for the next centuries.

In order to draw conclusions about future availability of exhaustible resources, it is necessary to have a closer look on the amount of proved and other reserves of a resource in comparison with its production rates.

For the exhaustible energy resources crude petroleum and natural gas, it is possible to plot the reserveproduction ratio for the observed time period, see Fig. 5. The smaller the ratio the scarcer is the natural resource. For petroleum and natural gas, the trend is declining, thus, proved reserves will be depleted soon if for example, extensions/discoveries of new fields in already discovered regions or new discoveries do not make reserve additions possible.

Every year, the Energy Information Administration and the US Geological Survey estimate quantities of technically recoverable resource amounts that could be added to the already proved reserves of the US. It is interesting to ask about the number of years it will take to exhaust the today estimated technical recoverable resources quantities. As the production rates of the energy resources, coal and natural gas are steadily

TABLE I Fuel mineral production per dollar real GDP

\begin{tabular}{lccc}
\hline & & & Natural gas in millions of \\
cubic feet & Coal in short tons & $6.3155 \times 10^{-6}$ \\
1960 & Crude petroleum barrels & $2.0526 \times 10^{-4}$ & $3.1316 \times 10^{-6}$ \\
1995 & $1.2680 \times 10^{-3}$ & $1.6589 \times 10^{-4}$ & -48 \\
Change (\%) & $3.8447 \times 10^{-4}$ & -19 & -40 \\
\hline
\end{tabular}

TABLE II Non-fuel mineral production per dollar real GDP

\begin{tabular}{lcccc}
\hline & Copper in short tons & Iron ore in short tons & Lead in short tons & Zinc in short tons \\
\hline 1960 & $5.3287 \times 10^{-4}$ & $4.0952 \times 10^{-2}$ & $1.2187 \times 10^{-4}$ & $2.1463 \times 10^{-4}$ \\
1995 & $2.9700 \times 10^{-3}$ & $9.8124 \times 10^{-3}$ & $6.1990 \times 10^{-5}$ & $9.8605 \times 10^{-5}$ \\
Change (\%) & -44 & -76 & -49 & -54 \\
\hline
\end{tabular}




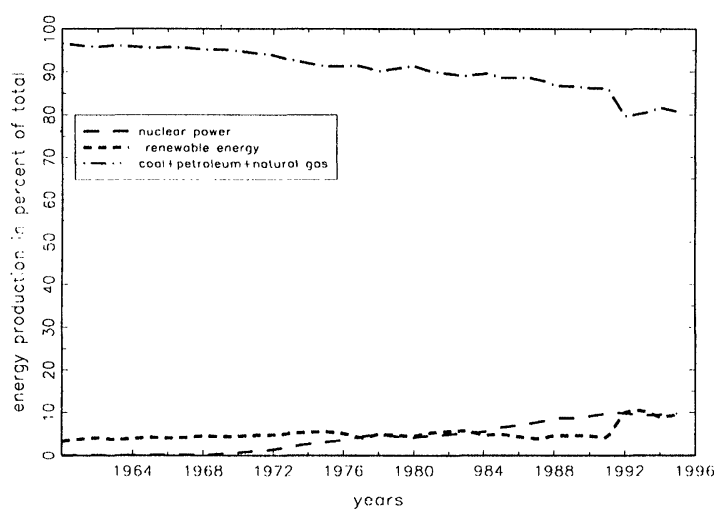

FIGURE 4 Energy production sources in percent of total.

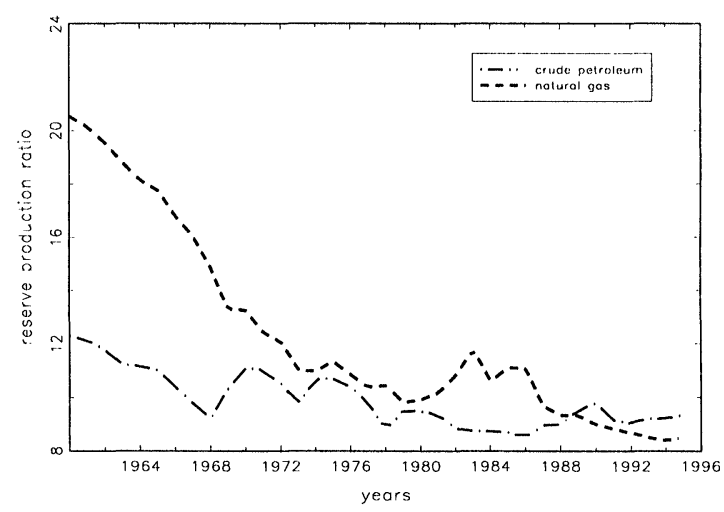

FIGURE 5 Reserve-production ratio. increasing during the observed time period, it is assumed that they continue to increase with an average production growth rate. The other resources do not show any clear trend in their production rates and, therefore, it is supposed that production will continue to follow a stable pattern during the next years. Tables III-V summarize the results.

Although the results of the empirical analysis are restricted by the length of the examined time period and there is a clear decline and finiteness of resources, yet, there may be technological progress that makes a further development of renewable substitutes for exhaustible resources possible. As the US economy has experienced continued economic growth during the second half of this century, the production rates of exhaustible resources have risen and for all analyzed minerals, the production per dollar real GDP has declined. Increased efficiency, as the consequence of advanced technology and the use of close substitutes are likely explanations for that fact.

Assuming no changes in production trends yields predictions of the number of years left until present estimated resource reserves are depleted. The estimated reserves of coal and natural gas will last for the next two or three centuries. As the present estimated reserves of crude petroleum would be depleted in 40 years, the US economy is dependent on oil imports mainly from Arab countries. Substitutes of coal, natural gas and crude petroleum are nuclear and renewable power. Since the share of these alternative energy production sources has increased from 1960 to 1995 , it seems likely that further

TABLE III Estimated reserves of petroleum and natural gas 1995

\begin{tabular}{lcc}
\hline & Crude petroleum in bill bbl & Natural gas in trill (cu. ft) \\
\hline Proved reserves & 20.2 & 135 \\
Field growth & 60.0 & 322 \\
Undiscovered resources & 30.3 & 259 \\
Total reserves & 110.5 & 716 \\
Average annual production/average production growth rate & 3.0076 & 0.012 \\
Years left until exhaustion & 40 & 300 \\
\hline
\end{tabular}

TABLE IV Estimated reserves of coal 1996

\begin{tabular}{lcccr}
\hline Proved reserves & Other reserves & Total reserves & Average production growth rate & Year left until exhaustion \\
\hline 19,428 & 507,740 & 527,168 & 0.026 & 250 \\
\hline
\end{tabular}

TABLE V Estimated reserves of some selected metals 1997

\begin{tabular}{lcccc}
\hline & $\begin{array}{c}\text { Copper in 1000 } \\
\text { metric tons }\end{array}$ & $\begin{array}{c}\text { Iron ore in 1000 } \\
\text { metric tons }\end{array}$ & $\begin{array}{c}\text { Lead in 1000 } \\
\text { metric tons }\end{array}$ & $\begin{array}{c}\text { Zinc in 1000 } \\
\text { metric tons }\end{array}$ \\
\hline Proved reserves & 45000 & 10000000 & 6500 & 25000 \\
Other reserves & 90000 & 23000000 & 20000 & 80000 \\
Total reserves & 135000 & 33000000 & 26500 & 439.72 \\
Average annual production & 1414.25 & 68844.44 & 6000 & 437.14 \\
Years left until exhaustion & 95 & 480 & 240 \\
\hline
\end{tabular}


research and development will enhance this trend. The reserves of iron ore and zinc are very high while lead and copper seem to be rather scarce. Yet, an increased use of particularly plastics as a renewable substitute may relax the constraints that a sustainable development faces.

These predictions are all made under the assumption that only currently available technology is applied. It seems to be likely that technological progress improves for example, mining and refining methods or makes discoveries of new resources fields possible, and, therefore, enhances present estimations of available reserves. In order to ensure sustainable growth in the sense of minimal degradation of natural capital stocks and intergenerational equity, it appears to be important to develop further renewable substitutes.

\section{ESTIMATION OF THE MODEL}

In order to estimate the growth model as described in "Modern Growth Models and Resource Constraints," first, consumer preferences and the technology of producing goods have to be specified, and, second, a data set has to be constructed. In our estimation, we focus on the standard model as presented in "The Basic Model."

It is assumed that the natural resource contributes to economic activity only in one way: it is used as an input factor for the production of a commodity, which is either consumed or added to the capital stock. The present value of utility received from consumption is given by

$$
\int_{0}^{\infty} \frac{C_{t}^{1-\eta}-1}{1-\eta} e^{-\delta t} \mathrm{~d} t
$$

where, $\eta$ is the elasticity of marginal utility. The technology of goods is described by a Cobb-Douglasproduction function, which depends on reproducible capital $K_{t}$ and the exhaustible resource flow $R_{t}$. The elasticity of substitution between reproducible capital and the exhaustible resource $\sigma$ equals 1 . The evolution of capital is determined by

$$
\dot{K}_{t}=K_{t}^{\beta} R_{t}^{1-\beta}-C_{t}
$$

$\beta$ denotes the share of reproducible capital in production. Maximizing present value of utility and setting $y_{t}=C_{t} / R_{t}$ yields the following estimable system: for a detailed study of the solution, see "Estimation Section" in the Appendix A.

$$
\begin{gathered}
\frac{\dot{y}_{t}}{y_{t}}=\frac{\beta x_{t}^{\beta-1}-\delta}{\eta}-\phi \\
\frac{\dot{x}_{t}}{x_{t}}=x_{t}^{\beta-1} \\
\frac{\dot{R}_{t}}{R_{t}}=\phi
\end{gathered}
$$

TABLE VI Estimation results

\begin{tabular}{llc}
\hline Parameter & Value & Standard error \\
\hline$\beta$ & 0.32 & 3.4668 \\
$\bar{\delta}$ & 0.03 & 0.0369 \\
$\bar{\eta}$ & 0.5 & 0.2488 \\
$\phi$ & 0.002 & 0.1856 \\
\hline
\end{tabular}

with $\phi$ as the growth rate of the exhaustible resource flow.

As time series data, we need consumption, reproducible capital stock $^{\text {IIII }}$ and the exhaustible resource flow. ${ }^{\# \#}$ The reproducible capital stock, $K_{t}$, is gross real private fixed capital stock and $C_{t}$ is private consumption. The time series for the resource, $R$, is based on our own computation. Since the total mineral production value is the amount of extracted exhaustible resources times average prices, it is used to measure the exhaustible resource flow. All time series are deflated by the GDPprice index $1990=100$.

Equations (16)-(18) are estimated directly by using non-linear least squares techniques (NLLS). ${ }^{* * *}$ In the estimation, we have prefixed the discount rate, $\bar{\delta}$, and the parameter of relative risk aversion, $\bar{\eta}$. The reason for this procedure is that the model we are considering-leaving aside substitution, technological change and the role of other inputs-is in its current form, rather incomplete and reliable estimates for the discount rate as well as for relative risk aversion, cannot be expected. Therefore, we prefix them at levels that have been obtained by other recent studies (see Semmler and Gong, 1997). This procedure can be understood as a calibration exercise rather than estimation. The results are summarized in Table VI.

The estimated capital share in income, $\beta$, and the estimated growth rate of the resource flow, $\phi$, are reasonable.

Although there is a very irregular behavior of the total mineral production value over the observed time period, the data show an enormous increase of the value of resources in the years 1972-1981 caused by the price effects of the oil crisis.

Figures 6 and 7 show the estimated (fitted) and actual time series for the ratio of capital stock to resources and the ratio of consumption to resources. Both figures show that there is, in particular, since 1980, a strong trend toward the depletion of resources relative to capital stock and consumption.

As the figures show, the model with our estimated parameters matches the data well. As already noted, the very simple structure of the model may explain the observable slight correlation of the error terms. We also have supposed that population remains constant which implies that labor as an input factor in production is

\footnotetext{
IIIIData on consumption and capital stock are obtained from Citibase (1998).

${ }^{\#}$ Source: US Department of Commerce, Economics and Statistics, Bureau of the Census 1965-1997.

${ }^{* * *}$ Computed with GAUSS-OPTMUM version 3.00 .
} 


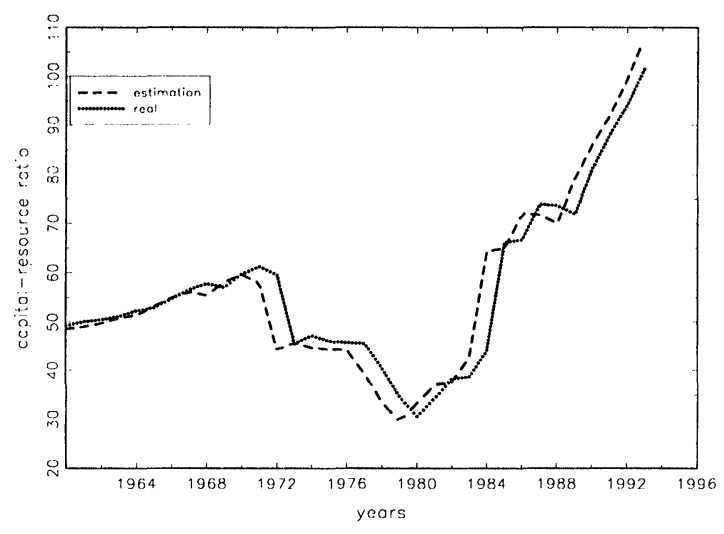

FIGURE 6 Capital-resource ratio.

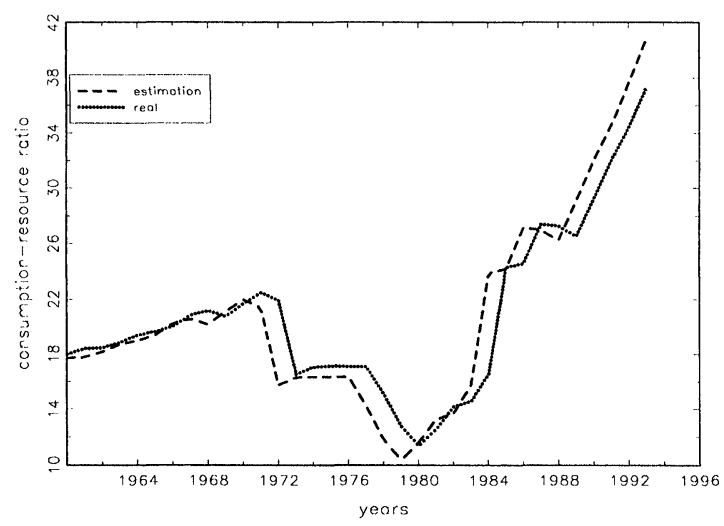

FIGURE 7 Consumption-resource ratio.

constant, too. This assumption seems justified when analyzing the very short-run, but not appropriate when examining a time period of 35 years. It seems to be likely that incorporating the factor labor into the model would improve the estimation results. Such an improvement is particularly critical for our estimation result on $\beta$, since our estimate gives a value of $\beta=0.32$. This would mean, according to Solow (1973), that sustained per capita growth is not feasible (see "The Basic Model"). Improvement of our estimations by including further factors would most likely give us the result that exhaustible resource share in production, $1-\beta$, is likely to be smaller. Furthermore, as the stylized facts support, it would be reasonable to allow technological progress and substitution. Finally, the quality of non-linear estimations depends strongly on the number of observations. Since the analyzed time period consist of only 35 data points, it is difficult to achieve sufficient robustness in the estimations. This problem was clearly observable, when we attempted to estimate the prefixed parameters $\bar{\eta}$ and $\bar{\delta}$. Their estimation in fact turned out to be non-robust with respect to the algorithm used. We therefore kept them prefixed.

In summary, although our preliminary results may be illuminating, future research should take into account the factor labor and technological progress and substitution, and to estimate such a model over a longer time period or with data with a higher frequency.

\section{CONCLUSIONS}

This paper attempts to study in a formal model, the growing concern that human activity and economic growth depletes natural resources. Although both, renewable as well as exhaustible resources are threatened by extinction in the process of economic growth ${ }^{* * * *}$ this paper in particular focuses on exhaustible economic resources. We pursue the question of whether the current rate of extraction of exhaustible resources is sustainable given the present pattern of economic growth. We present time series data and give rough estimates of depletion time for exhaustible resources. We also study the problem of intergenerational equity and the different criteria that have been suggested in the literature to conserve resources and do justice to future generations. In a particular growth model, we study to what extent resource constraints can be overcome by technological change and substitution. Although it would be advisable to consider worldwide trends in the exhaustion of resources, we because of data problems, restrain our study to empirical trends and stylized facts on exhaustible resources of the US economy. We estimate a standard growth model with resource constraints for US time series data. We can observe from our time series data that there is, disruption by the strong increase of the value of resources due to the oil crisis in the 1970s, a strong decrease of the use of resources relative to capital stock and consumption since 1980. Our econometric estimations concerning the capital share point into the opposite direction. Yet, our estimates, in particular our estimate of the capital share, which indicates-if one follows Solow (1973) - non-sustainable growth, has to be interpreted with some care since the estimated growth model lacks other variables, uses limited time series and low frequency data. Moreover, the lack of data on technological change and substitutes for exhaustible resources prevents us from drawing the strong conclusion that there is a threat to sustainable growth in the future. Yet, the ratio of capital stock or consumption to resources has tripled, possibly indicating future problems concerning the availability of exhaustible resources or this also may indicate that technical change and substitution has reduced the use of resources.

\section{Acknowledgements}

We would like to thank Toichiro Asada for his helpful comments.

\footnotetext{
${ }^{* * * *}$ For studies on the extinction of renewable resources, see Clark, 1990; Semmler and Sieveking 1994, 1997, 2000.
} 


\section{References}

Beltratti, A. (1993) "Sustainable growth: models and policy implications", In: Boero, Gianna and Silberston, Aubrey, eds, Environmental Economics Proceedings of a conference held by the Confederation of European Economic Associations at Oxford, pp 296-311.

Beltratti, A. (1995) "Intergenerational equity and environmental preservation", Nota Di Lavoro, 1-15.

Beltratti, A. (1996) Models of Economic Growth with Environmental Assets (Kluwer Academic Publishers, Dordrecht).

Beltratti, A., Chichilnisky, G. and Heal, G.M. (1993) Sustainable Growth and the Green Golden Rule NBER Working Paper Series, No. 4430.

Beltratti, A., Chichilnisky, G. and Heal, G.M. (1994) "The environment and the long run: a comparison of different criteria", Richerche Economiche 48, 319-340.

Chichilnisky, G. (1996) "An Axiomatic Approach to Sustainable Development", Social Choice and Welfare 13(2), 219-248, What is sustainable Development? Paper presented at Stanford Institute for Theoretical Economics, 1993.

Clark, C. (1990) Mathematical Bioeconomics (Wiley, New York).

Daly, H.E. (1987) "The economic growth debate: what some economists have learned but many have not", Journal of Environmental Economics and Management 14(4), 323-336.

Daly, H. and Cobb, J.B. (1989) For the Common Good: Redirecting the Economy toward Community, the Environment and a Sustainable Future (Beacon Press, Boston).

Dasgupta, P. (1994) "Exhaustible resources: resource depletion, research and development and the social rate of discount", In: Layard, Richard and Glaister, Stephen, eds, Cost-benefit Analysis (Cambridge University Press, Cambridge).

Dasgupta, P. and Heal, G.M. (1974) "The optimal depletion of exhaustible resources", Review of Economic Studies Symposium on the Economics of Exhaustible Resource, pp 3-28.

Dasgupta, P. and Heal, G.M. (1979) Economic Theory and Exhaustible Resources (Cambridge University Press, Welwyn), Cambridge.

Dasgupta, P., Heal, G.M. and Majumdar, M. (1993) "Resource depletion and research and development", In: Heal, Geoffrey, ed, The Economics of Exhaustible Resources International Library of Critical Writings in Economics, (Edward Elgar, Worcester).

Davison, R. (1978) "Optimal depletion of an exhaustible resource with research and development towards an alternative technology", Review of Economic Studies 45(2), 355-368.

Dixit, A., Hammond, P. and Hoel, M. (1980) "On Hartwick's rule for regular maximin paths of capital accumulation and resource depletion", Review of Economic Studies 47(3), 551-556.

Energy Information Administration. (1996) "Coal Industry Annual 1996", Executive Summary, http: //www.eia.doe.gov/cneaf/coal/cia/cia_sum.html.

Energy Information Administration. (1997) "US Crude Oil, Natural Gas, and Natural Gas Liquids Reserves 1997“, Annual Report (1997), http: //www.eia.doe.gov/oil_gas/natural_gas/nat_frame.html.

Hartwick, J.M. (1977) "Intergenerational equity and the investing of rents from exhaustible resources", Review of Economic Studies 67(5), 973-974.

Heal, G.M. (1985) "The optimal use of exhaustible resources", In: Kneese, Alan and Sweeney, James, eds, Handbook of Natural Resource and Energy Economics (North Holland, Amsterdam) Vol. 1.

Heal, G.M. (1993) "The relationship between price and extraction cost for a resource with a backstop technology", In: Heal, Geoffrey, ed, The Economics of Exhaustible Resources International Library of Critical Writings in Economics, (Edward Elgar, Worcester).

Heal, G.M. (1995) "Interpreting sustainability", Nota Di Lavoro 1, 1-14.

Heal, G.M. (1998) Valuing the Future, Economic Theory and Sustainability (Columbia University Press, Columbia).

Krautkraemer, J.A. (1985) "Optimal growth, resource amenities and the preservation of natural environments", Review of Economic Studies 52, 153-171.

Meadows, D.H., Meadows, D.L., Randers, J. and Behrens, W.W. (1972) The Limits to Growth (Universe Books, New York).

Meadows, D.H., Meadows, D.L. and Randers, J. (1992) Beyond the Limits (Chelsea Green Publishing Company, Post Mills).

Nordhaus, W.D. (1992) "Lethal model 2: the limits to growth revisited", Brookings Papers on Economic Activity 2, 1-59.

Nordhaus, W.D. (1992) “Is growth sustainable? Reflections on the concept of sustainable economic growth", Paper presented to the International Economic Association Conference, Varenna, Italy.
Oren, S.S. and Powell, S.G. (1993) "Optimal supply of a depletable resource with a backstop technology: Heal's theorem revisited", In: Heal, Geoffrey, ed, The Economics of Exhaustible Resources International Library of Critical Writings in Economics, (Edward Elgar, Worcester), Aldershot.

Pezzey, J., (1989) "Economic analysis of sustainable growth and sustainable development". The World Bank Policy Planning and Research Staff, Environment Department Working Paper No. 15

Phelps, E.S. (1961) "The golden rule of accumulation: a fable for growthmen", American Economic Review, 638-643.

Ramsey, F. (1928) "A mathematical theory of saving", Economic Journal 38, 543-559.

Rawls, J. (1972) A Theory of Justice (Clarendon, Oxford).

Semmler, W. and Gong, G. (1997) "Estimating parameters of real business cycle models", Journal of Economic Behaviour and Organization 30, 301-325.

Semmler, W. and Sieveking, M. (1994) "On the optimal exploitation of interacting resources", Journal of Economics 59(1).

Semmler, W. and Sieveking, M. (2000) "Debt dynamics and sustainable debt”, Journal of Economic Dynamics and Control 24, 1121-1144.

Sieveking, M. and Semmler, W. (1997) "The present value of resources with large discount rates", Applied Mathematics and Optimization 38, 283-309.

Solow, R.M. (1973) "Is the end of the world at hand?", In: Weintraub, Andrew, Schwartz, Eli and Richard Aronson, J., eds, The Economic Growth Controversy (International Arts and Sciences Press, New York).

Solow, R.M. (1974) "Intergenerational equity and exhaustible resources", Review of Economic Studies Symposium on the Economics of Exhaustible Resources, pp 29-45.

Solow, R.M. (1991) Sustainability: an economist's perspective 18th J. Seward Johnson Lecture, (Marine Policy Center.

Solow, R.M. (1992). "An almost practical step toward sustainability", An Invited Lecture on the Occasion of the 40th Anniversary of Resources for the Future.

Stiglitz, J.E. (1974) "Growth with exhaustible natural resources: efficient and optimal growth paths", Review of Economic Studies Symposium on the Economics of Exhaustible Resources, pp 123-137.

Stiglitz, J.E. (1993) "A neoclassical analysis of the economics of natural resources", In: Heal, Geoffrey, ed, The Economics of Exhaustible Resources International Library of Critical Writings in Economics, (Edward Elgar, Worcester), Aldershot.

Toman, M.A., Pezzey, J. and Krautkraemer, J.A. (1993) "Neoclassical economic growth theory and sustainability", In: Bromley, Daniel W. ed, Handbook of Environmental Economics (Blackwell Press, Oxford, UK).

US Department of Commerce, Economics and Statistics, Bureau of the Census (1965-1997) Statistical Abstract of the United States.

US Geological Survey (1995a) A Summary of the US Geological Survey, http: //energy.usgs.gov/factsheets/N Aresults/nat.assess.num ber.html.

US Geological Survey (1995b) National Assessment of Oil and Gas Resources, http: //energy.usgs.gov/products/factsheets/FS02498/index.html

US Geological Survey (1997) Minerals Information, http: //minerals.usgs.gov.

US Geological Survey (1999) Mineral Commodity Summary/http: //minerals.usgs.gov.

Weizäcker, C.C. (1967) "Lemmas for a Theory of Approximate Optimal Growth", Review of Economic Studies, 143-151.

World Commission on Environment and Development (1987) Our Common Future (the Brundtland Report) (Oxford University Press, New York)

\section{APPENDIX A}

\section{The Basic Model}

The following maximization problem must be solved:

$$
\operatorname{Max} \int_{0}^{\infty} U\left(C_{t}\right) e^{-\delta t} \mathrm{~d} t
$$


subject to

$$
\dot{K}_{t}=F\left(K_{t}, R_{t}\right)-C_{t}, \quad S_{t}=S_{0}-\int_{0}^{\infty} R_{t} \mathrm{~d} t \quad \dot{S}_{t}=-R_{t}
$$

The current value Hamiltonian is defined as

$$
H_{c}=U\left(C_{t}\right)+p_{t}\left(-R_{t}\right)+q_{t}\left(F\left(K_{t}, R_{t}\right)-C_{t}\right)
$$

where $p_{t}$ denotes the shadow price of the resource constraint and $q_{t}$ denotes the shadow price of capital accumulation. Computing the first order conditions yields the following equations, which must be fulfilled along an optimal path:

$$
\begin{gathered}
\dot{p}_{t}=\delta p_{t} \\
U^{\prime}\left(C_{t}\right)=q_{t} \\
p_{t}=q_{t} F_{R} \\
\dot{q}_{t}-\delta q_{t}=-q_{t} F_{K}
\end{gathered}
$$

with $F_{R}=\partial F\left(K_{t}, R_{t}\right) / \partial R_{t}$ and $F_{K}=\partial F\left(K_{t}, R_{t}\right) / \partial K_{t}$. Differentiating Eq. (A4) with respect to time and substituting Eq. (A6) yields the consumption rate along an optimal path:

$$
\frac{\dot{C}_{t}}{C_{t}}=\frac{F_{K}-\delta}{\eta}
$$

Differentiating Eq. (A5) with respect to time and using Eqs. (A3) and (A6) results in

$$
F_{K}=\frac{\partial F_{R}}{\partial t} \frac{1}{F_{R}}
$$

Substituting $F_{R}=f\left(x_{t}\right)-x_{t} f^{\prime}\left(x_{t}\right)$ and $F_{K}=f^{\prime}\left(x_{t}\right)$ with $f\left(x_{t}\right)=F\left(\left(K_{t} / R_{t}\right), 1\right)$ and $x_{t}=K_{t} / R_{t}$ in Eq. (A8) yields the capital-resource ratio along an optimal path:

$$
\frac{\dot{x}_{t}}{x_{t}}=\sigma \frac{f\left(x_{t}\right)}{x_{t}}
$$

\section{Technology}

The following maximization problem must be solved:

$$
\operatorname{Max} \int_{0}^{\infty}\left[U\left(C_{t}\right) \Omega_{t}+\omega_{t} W\left(K_{t}, S_{t}\right)\right] e^{-\delta t} \mathrm{~d} t
$$

subject to

$$
\dot{K}_{t}=F\left(K_{t}, R_{t}\right)-C_{t} \quad S_{t}=S_{0}-\int_{0}^{\infty} R_{t} \mathrm{~d} t \quad \dot{S}_{t}=-R_{t}
$$

The current value Hamiltonian is

$$
\begin{aligned}
H_{c} & =U\left(C_{t}\right) \Omega_{t}+\omega_{t} W\left(K_{t}, S_{t}\right) \\
& +p_{t}\left(-R_{t}\right)+q_{t}\left(F\left(K_{t}, R_{t}\right)-C_{t}\right)
\end{aligned}
$$

Computing the first order conditions yields

$$
\begin{gathered}
\dot{p}_{t}=\delta p_{t} \\
\Omega_{t} U^{\prime}\left(C_{t}\right)=q_{t} \\
p_{t}=\omega_{t} W_{S}+q_{t} F_{R} \\
\dot{q}_{t}-\delta q_{t}=-\omega_{t} W_{K}-q_{t} F_{K}
\end{gathered}
$$

Differentiating Eq. (A13) with respect to time and substituting Eq. (A15) results in

$$
\frac{\dot{C}_{t}}{C_{t}}=\frac{F_{K}-\delta+\psi_{t}\left(W_{K}-U^{\prime}\left(C_{t}\right)\right) / U^{\prime}\left(C_{t}\right)}{\eta}
$$

with $\psi_{t}=\omega_{t} / \Omega_{t}$. If $W_{k}=W_{S}=0$, one gets the following consumption rate along an optimal path:

$$
\frac{\dot{C}_{t}}{C_{t}}=\frac{F_{K}-\left(\delta+\psi_{t}\right)}{\eta}
$$

\section{Backstop Technology}

The following maximization problem must be solved

$$
\operatorname{Max} \int_{0}^{\infty} U\left(C_{t}\right) e^{-\delta t} \mathrm{~d} t
$$

subject to

$$
\begin{gathered}
\dot{K}_{t}=F\left(K_{t}, R_{t}\right)-C_{t}-g\left(z_{t}\right) R_{t}, \quad S_{t}=S_{0}-\int_{0}^{\infty} R_{t} \mathrm{~d} t, \\
\dot{S}_{t}=-R_{t}
\end{gathered}
$$

where $g\left(z_{t}\right) R_{t}$ represents the total extraction costs. The current value Hamiltonian is

$$
\begin{aligned}
H_{c}= & U\left(C_{t}\right)+p_{t}\left(-R_{t}\right)+q_{t}\left(F\left(K_{t}, R_{t}\right)-C_{t}\right. \\
& \left.-g\left(z_{t}\right) R_{t}\right)
\end{aligned}
$$

Computing the first order conditions yields

$$
\begin{gathered}
\dot{p}_{t}=\delta p_{t}+q_{t} g^{\prime}\left(z_{t}\right) R_{t}=\delta p_{t} q_{t} g^{\prime}\left(z_{t}\right) \dot{z}_{t} \\
=\delta p_{t} q_{t} \frac{\partial g\left(z_{t}\right)}{\partial t} \\
U^{\prime}\left(C_{t}\right)=q_{t} \\
-p_{t}=q_{t}\left(F_{R}-g\left(z_{t}\right)\right) \\
\dot{q}_{t}-\delta q_{t}=-q_{t} F_{K}
\end{gathered}
$$

Differentiating Eq. (A22) with respect to time and using Eqs. (A20) and (A23) results in

$$
F_{K}=\frac{\partial F_{R}}{\partial t} \frac{1}{F_{R}}+\frac{F_{K} g\left(z_{t}\right)}{F_{R}}
$$

Substituting $F_{R}=f\left(x_{t}\right)-x_{t} f^{\prime}\left(x_{t}\right)$ and $F_{K}=f^{\prime}\left(x_{t}\right)$ in Eq. (A24) results in the following capital-resource ratio 
along an optimal path:

$$
\frac{\dot{x}_{t}}{x_{t}}=\frac{\sigma f\left(x_{t}\right)}{x_{t}}+\frac{f^{\prime}\left(x_{t}\right)}{x_{t} f^{\prime \prime}\left(x_{t}\right)} \frac{g\left(z_{t}\right)}{x_{t}}
$$

\section{The Amenity Value of a Natural Resource}

The following maximization problem must be solved

$$
\operatorname{Max} \int_{0}^{\infty} U\left(C_{t}, S_{t}\right) e^{-\delta t} \mathrm{~d} t
$$

subject to

$$
\dot{K}_{t}=F\left(K_{t}, R_{t}\right)-C_{t} \quad S_{t}=S_{0}-\int_{0}^{\infty} R_{t} \mathrm{~d} t \quad \dot{S}_{t}=-R_{t}
$$

The current value Hamiltonian is defined as

$$
H_{c}=U\left(C_{t}, S_{t}\right)+p_{t}\left(-C_{t}\right)+q_{t}\left(F\left(K_{t}, R_{t}\right)-C_{t}\right)
$$

Computing the first order conditions yields

$$
\begin{gathered}
\dot{p}_{t}-\delta p_{t}=-U_{S} \\
U_{C}=q_{t} \\
p_{t}=q_{t} F_{R} \\
\dot{q}_{t}-\delta q_{t}=-q_{t} F_{K}
\end{gathered}
$$

Differentiating Eq. (A29) with respect to time and substituting Eq. (A31) results in the following consumption rate along an optimal path:

$$
\frac{\dot{C}_{t}}{C_{t}}=\frac{F_{K}-\delta-\left(U_{\mathrm{CS}} / U_{C}\right) R_{t}}{\eta}
$$

Differentiating Eq. (A30) with respect to time and using Eqs. (A28) and (A31) yields

$$
F_{K}=\frac{\partial F_{R}}{\partial t} \frac{1}{F_{R}}+\frac{U_{S} / U_{C}}{F_{R}}
$$

Substituting $F_{R}=f\left(x_{t}\right)-x_{t} f^{\prime}\left(x_{t}\right)$ and $F_{K}=f^{\prime}\left(x_{t}\right)$ in Eq. (A33) yields the following capital-resource ratio

$$
\frac{\dot{x}_{t}}{x_{t}}=\sigma \frac{f\left(x_{t}\right)}{x_{t}}+\frac{U_{S} / U_{C}}{x_{t}^{2} f^{\prime \prime}\left(x_{t}\right)}
$$

\section{Estimation}

The following maximization problem has to be solved:

$$
\operatorname{Max} \int_{0}^{\infty} \frac{C_{t}^{1-\eta}}{1-\eta} e^{-\delta t} \mathrm{~d} t
$$

subject to

$$
\begin{gathered}
\dot{K}_{t}=K_{t}^{\beta} R_{t}^{1-\beta}-C_{t} \\
\dot{S}_{t}=-R_{t}
\end{gathered}
$$

The optimality conditions are

$$
\begin{gathered}
\frac{\dot{C}_{t}}{C_{t}}=\frac{F_{K}-\delta}{\eta} \\
\frac{\dot{x}_{t}}{x_{t}}=\frac{f\left(x_{t}\right)}{x_{t}}
\end{gathered}
$$

With $F_{K}=\beta K_{t}^{\beta-1} R_{t}^{1-\beta}=\beta\left(K_{t} / R_{t}\right)^{\beta-1}=\beta x_{t}^{\beta-1}$ and $F\left(K_{t} / R_{t}, 1\right)=f\left(x_{t}\right)=x^{\beta}$ one gets:

$$
\begin{gathered}
\frac{\dot{C}_{t}}{C_{t}}=\frac{\beta x_{t}^{\beta-1}-\delta}{\eta} \\
\frac{\dot{x}_{t}}{x_{t}}=x_{t}^{\beta-1}
\end{gathered}
$$

Setting $y_{t}=C_{t} / R_{t}$ yields $\dot{y}_{t} / y_{t}=\left(\dot{C}_{t} / C_{t}\right)-\left(\dot{R}_{t} / R_{t}\right)$ and the following estimable system is obtained:

$$
\begin{gathered}
\frac{\dot{y}_{t}}{y_{t}}=\frac{\beta x_{t}^{\beta-1}-\delta}{\eta}-\phi \\
\frac{\dot{x}_{t}}{x_{t}}=x_{t}^{\beta-1} \\
\frac{\dot{R}_{t}}{R_{t}}=\phi
\end{gathered}
$$

where $\phi$ denotes the growth rate of the resource flow.

\section{APPENDIX B}

\section{Data Sources}

- Annual data from 1960 to 1995 for the following time series are, taken from the US Department of Commerce, Economics and Statistics, Bureau of the Census (1965-1997):

crude petroleum production;

coal production; natural gas production;

copper production;

iron ore production;

zinc production;

lead production;

share of nuclear power, renewable energy and fuel minerals in total energy production;

total mineral production value; proved reserves of crude petroleum and natural gas; gross private consumption; and accumulated gross fixed capital formation.

- Estimated reserves of crude petroleum and natural gas are from US Geological Survey (1995a): 
proved reserves;

field growth;

undiscovered resources; and

total reserves.

- Estimated reserves of coal are from Energy Information Administration (1996):

proved reserves; other reserves; and total reserves.

- Estimated reserves of copper, iron ore, lead and zinc are from US Geological Survey (1999):

proved reserves;

other reserves; and total reserves. 


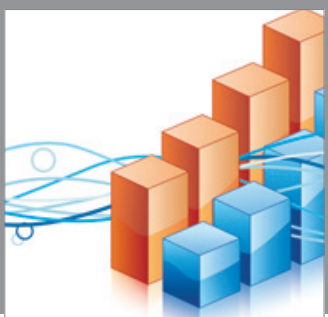

Advances in

Operations Research

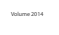

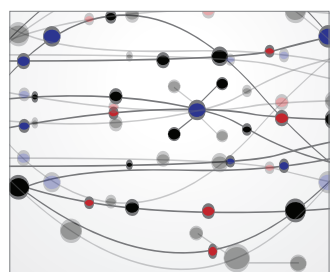

\section{The Scientific} World Journal
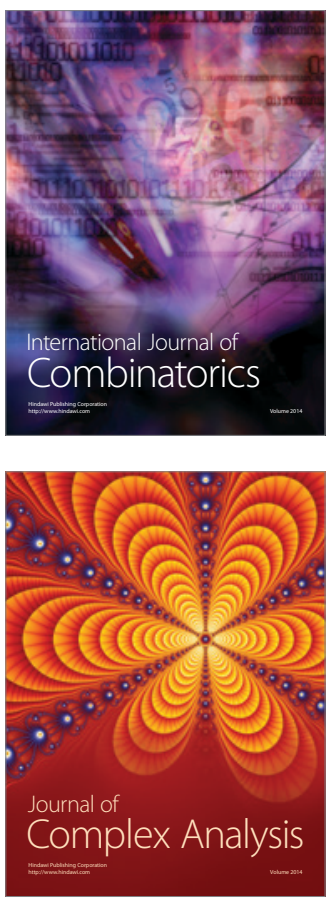

International Journal of

Mathematics and

Mathematical

Sciences
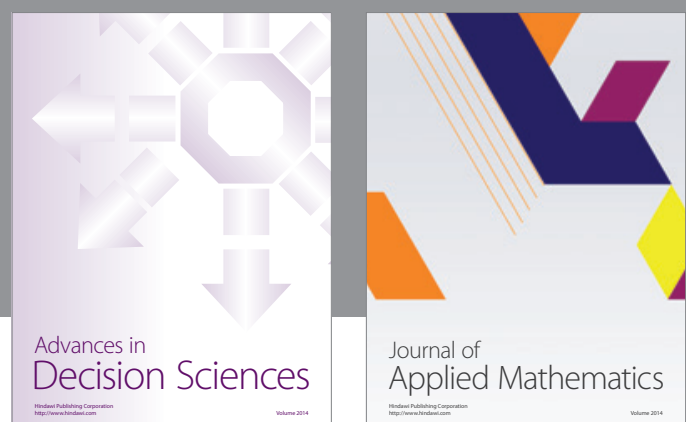

Journal of

Applied Mathematics
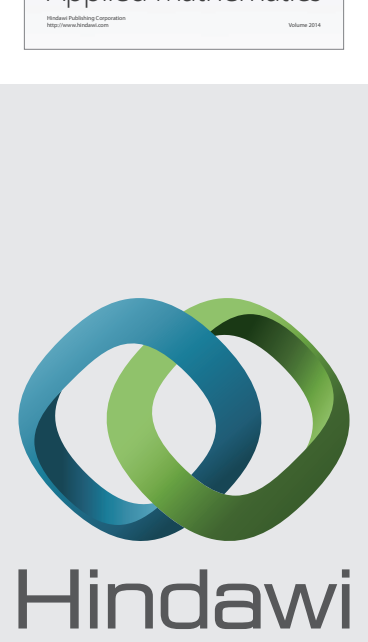

Submit your manuscripts at http://www.hindawi.com
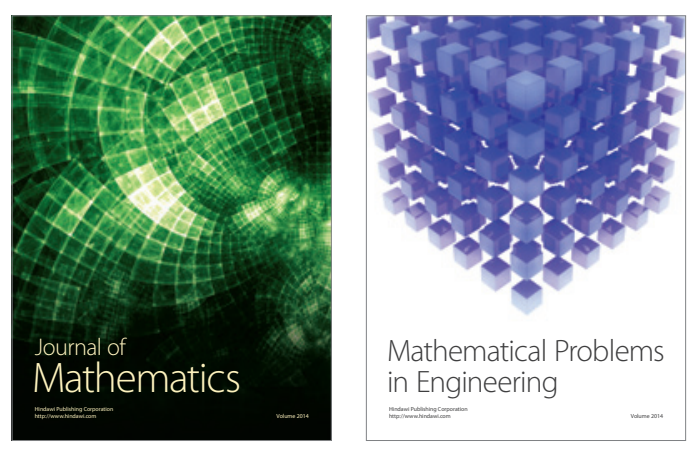

Mathematical Problems in Engineering
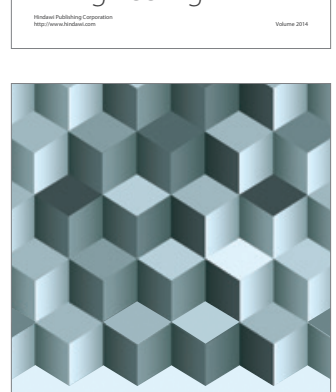

Journal of

Function Spaces
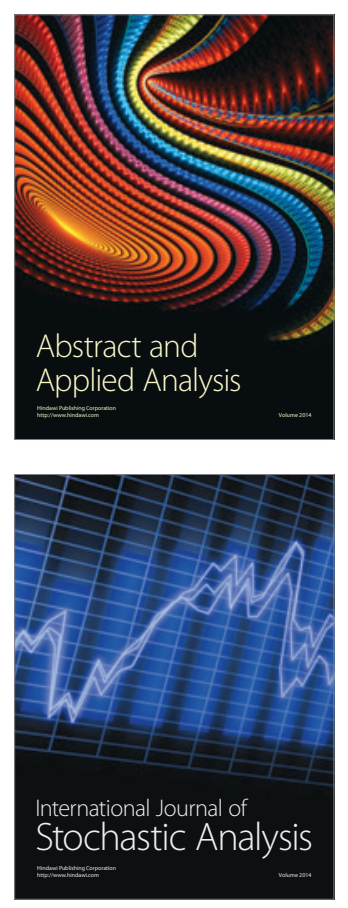

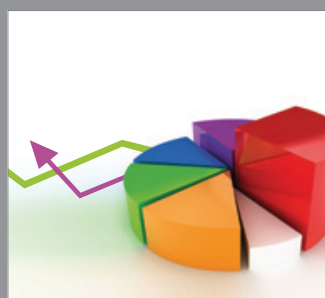

ournal of

Probability and Statistics

Promensencen
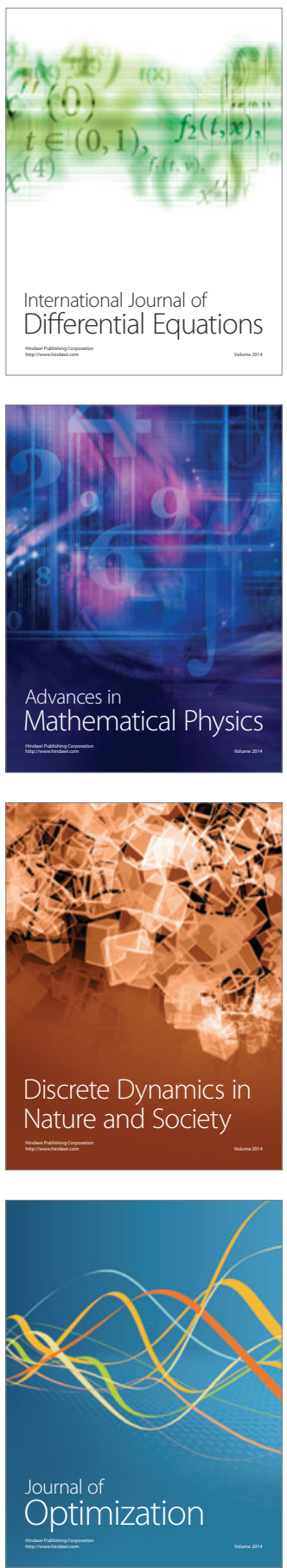